\title{
Effective bronchodilator treatment by a simple spacer device for wheezy premature infants
}

\author{
B Yuksel, A Greenough, I Maconochie
}

\begin{abstract}
Ten preterm infants with recurrent respiratory symptoms (median gestational age $\mathbf{3 0}$ weeks) were entered into a non-randomised placebo controlled trial of bronchodilator treatment at 12.5 months of age. The infants had coughed or wheezed, or both, on at least four days a week for the past month. The infants received either placebo or $500 \mu \mathrm{g}$ terbutaline from an inhaler using a coffee cup as a spacer device. Each treatment was maintained for two weeks, first placebo then active drug. The symptom score was reduced by $65 \%$ during the active treatment period compared with the placebo period and this was associated with a $32 \%$ improvement in lung function, reflected in an increase in functional residual capacity. We conclude that inhaled bronchodilator treatment given with a simple spacer device is useful for preterm infants with recurrent respiratory symptoms in the first two years of life.
\end{abstract}

Respiratory problems are common after discharge from neonatal intensive care. ${ }^{12}$ Infants require readmission to hospital for chest related disorders, ${ }^{3}$ and abnormalities of respiratory function may be detected as late as 8 to 10 years of age. ${ }^{4}$ Recurrent or persistent wheezing seems particularly common, Bowman and Yu reporting a high incidence of wheezing among extremely low birthweight infants during the first two years of life. ${ }^{5}$ Sauve and Singhal found an appreciable increase in abnormal breath sounds, most commonly wheezing, among chronic lung disease infants with chronic lung disease compared with controls. ${ }^{3}$ Smyth et al showed that recurrent wheezing and an increased frequency of lower respiratory tract infections occurred even at 8.4 years in infants with chronic lung disease who had been preterm. ${ }^{6}$ Although their study included only eight children, six of the eight had positive methacholine tests, and as a consequence the authors postulated that their episodic wheezing was the result of bronchial hyper-reactivity. ${ }^{5}$

The more frequent the episodes of wheezing in the first five years of life, the more likely is such a child to continue to wheeze up to 10 years of age. ${ }^{7}$ It is therefore imperative to use effective treatment and, most importantly, preventative measures.

In addition, we have often diagnosed persistent wheeze or cough, or both, among low birthweight infants at follow up, and it is twice as common as in controls born at full term. ${ }^{8}$ Surprisingly, however, few infants in our series had received treatment and even fewer specific drugs directed at treating or preventing this persistent wheeze. The aim of this study was to determine if regular bronchodilator treatment was efficacious for wheezy preterm infants during the first two years of life.

\section{Patients and methods}

Ten infants, six boys and four girls, median birth weight $1293 \mathrm{~g}$ (range 550-2440), median gestational age 30 weeks (range 25-36), and median postnatal age 12.5 months (range 8-26) were enrolled into the study. They all attended the paediatric respiratory clinic at this hospital. All the children had coughed or wheezed, or both, on at least four days a week for the past month. No infant was receiving treatment for the wheeze at the time of entry into the study, but one infant 9 months old was still oxygen dependent at home.

Permission for the study was granted by the King's College Hospital ethics committee.

The study period lasted four weeks: two weeks of placebo followed by two weeks of active treatment. The active drug was $500 \mu \mathrm{g}$ terbutaline. Both placebo and active drug were administered as two puffs twice a day from an inhaler using a coffee cup as a spacer device. At entry to the study and at the end of each two week period a clinical history was taken from the parents; the child was examined; and the height, weight, and respiratory function were measured.

During each two week period the parents completed a diary card regarding the need for medication or medical intervention and the nature and frequency of respiratory symptoms. The diary card had a scoring system of $0-3$ ( $0=$ none, $1=$ mild, 2 =moderate, $3=$ bad) for each of five symptom categories: 1-running nose, off feeds, unwell, 2-daytime wheezing, 3-night time wheezing, 4 -daytime coughing, and 5 -night time coughing. The parents noted the scores on each day (maximum daily score 15).

Lung function was assessed by measurement of functional residual capacity by a helium gas dilution technique. The measurements were made with the child in a semisupine position. The infant breathed through a face mask, held firmly in place to prevent leaks, into a water sealed spirometer (Gould Pulmonet 3). The spirometer incorporates a digital display of functional residual capacity, which was recorded at 15 second intervals. The measurement continued until there had been no change in the readout of functional residual capacity for 
30 seconds, when equilibration was assumed. All the traces were coded and analysed without knowledge of clinical details by AG. From the trace the equilibration point and end expiratory level were determined, and functional residual capacity calculated. The results were then converted to body temperature, pressure, and saturation conditions. The accuracy of the spirometer was checked daily with calibrated syringes.

Measurements of functional residual capacity were always made before and 10 minutes after $500 \mu \mathrm{g}$ terbutaline had been given as two puffs using a coffee cup as spacer. To assess the reproducibility of the measurements of functional residual capacity in young children, two separate measurements were made in 20 children of similar gestational age and postnatal age range to the study population. The mean of the differences between the 20 paired measurements was $2.0 \mathrm{ml} / \mathrm{kg}$. The intrasubject reproducibility was determined by calculation of the coefficient of variation of these measurements and was $7 \cdot 3 \%$. A clinically important change in functional residual capacity was therefore defined as one that was greater than $14.6 \%$.

Differences in the symptom scores and the measurements of functional residual capacity over the two week study periods were assessed

Table 1 Symptom scores (highest possible score: 210)

\begin{tabular}{lcc}
\hline Case No & Placebo period & Active period \\
\hline 1 & 39 & 0 \\
2 & 43 & 11 \\
3 & 72 & 30 \\
4 & 75 & 46 \\
5 & 105 & 30 \\
6 & 49 & 41 \\
7 & 45 & 29 \\
8 & 64 & 54 \\
9 & 60 & 1 \\
10 & 55 & 26 \\
\hline
\end{tabular}

Table 2 Changes in individual components of the symptoms score. Scores for each component are shown for the whole study group

\begin{tabular}{lll}
\hline & $\begin{array}{l}\text { Placebo period } \\
(n=10)\end{array}$ & $\begin{array}{l}\text { Active period } \\
(n=10)\end{array}$ \\
\hline Running nose/unwell & 106 & 77 \\
Wheeze: & & \\
Day & 152 & 81 \\
Night & 131 & 48 \\
Cough: & & \\
Day & 116 & 32 \\
Night & 116 & 30 \\
\hline
\end{tabular}

for significance using the Wilcoxon rank sum test or Fisher's exact test.

\section{Results}

Comparison of the symptom scores between the placebo and the active periods showed that there was a median reduction in symptom score of $65 \%$ in response to bronchodilator treatment $(\mathrm{p}<0.01)$ (table 1$)$. The greatest overall reduction in the symptom score occurred in night time wheeze (table 2). In two infants (aged 14 and 24 months) the symptom scores decreased by only $16 \%$ and $15 \%$, respectively (table 1 ).

There was no significant difference in the functional residual capacity measurements between the beginning and end of the placebo period, but the functional residual capacity improved by a median of $32 \%$ after two weeks of terbutaline administration $(p<0.01)$ (figure, table 3). Clinically important changes in measurements of functional residual capacity were found in 10 infants. There were significantly more infants who had clinically important changes in functional residual capacity after the active rather than the placebo period $(p<0.01$, Fisher's exact test): two after the placebo and

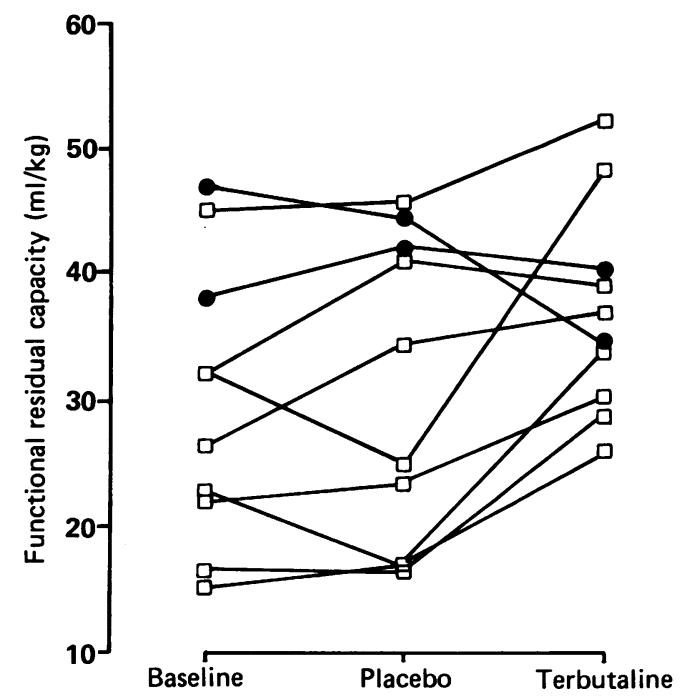

Functional residual capacity during the four week study period, individual patient's data points linked. In only one infant (who was chronically oxygen dependent) functional residual capacity decreased over the four weeks. The open squares indicate infants who made a clinically important improvements in functional residual capacity during the active period, and the closed circles infants who did not.

Table 3 Functional residual capacity ( $\mathrm{ml} / \mathrm{kg}$ ) for individual patients

\begin{tabular}{|c|c|c|c|c|c|c|c|}
\hline \multirow{2}{*}{$\begin{array}{l}\text { Age } \\
\text { (months) }\end{array}$} & \multirow{2}{*}{$\begin{array}{l}\text { Weight } \\
(\mathrm{kg})\end{array}$} & \multirow{2}{*}{$\begin{array}{l}\text { Height } \\
(\mathrm{cm})\end{array}$} & \multirow{2}{*}{$\begin{array}{l}\text { Baseline } \\
\text { value }\end{array}$} & \multicolumn{2}{|l|}{ Placebo } & \multicolumn{2}{|l|}{ Active } \\
\hline & & & & $\begin{array}{l}\text { Before } \\
\text { terbutaline }\end{array}$ & $\begin{array}{l}10 \mathrm{Min} \\
\text { after } \\
\text { terbutaline }\end{array}$ & $\begin{array}{l}\text { Before } \\
\text { terbutaline }\end{array}$ & $\begin{array}{l}10 \mathrm{Min} \\
\text { after } \\
\text { terbutaline }\end{array}$ \\
\hline $\begin{array}{r}8 \\
9 \\
9 \\
9 \\
11 \\
14 \\
18 \\
24 \\
26 \\
26\end{array}$ & $\begin{array}{r}8 \cdot 33 \\
4 \cdot 43 \\
7 \cdot 92 \\
6 \cdot 85 \\
7 \cdot 21 \\
10.63 \\
9 \cdot 80 \\
11 \cdot 80 \\
14 \cdot 10 \\
8 \cdot 40\end{array}$ & $\begin{array}{l}68 \cdot 0 \\
60 \cdot 5 \\
69 \cdot 5 \\
64 \cdot 6 \\
67 \cdot 2 \\
76 \cdot 0 \\
76 \cdot 8 \\
85 \cdot 0 \\
89 \cdot 0 \\
80 \cdot 0\end{array}$ & $\begin{array}{l}220 \\
209 \\
253 \\
220 \\
275 \\
175 \\
220 \\
176 \\
308 \\
378\end{array}$ & $\begin{array}{l}286 \\
198 \\
198 \\
280 \\
305 \\
175 \\
165 \\
198 \\
330 \\
385\end{array}$ & $\begin{array}{l}253 \\
242 \\
333 \\
256 \\
208 \\
286 \\
232 \\
210 \\
278 \\
396\end{array}$ & $\begin{array}{l}308 \\
154 \\
383 \\
268 \\
293 \\
308 \\
333 \\
308 \\
429 \\
440\end{array}$ & $\begin{array}{l}253 \\
220 \\
329 \\
306 \\
317 \\
331 \\
358 \\
231 \\
352 \\
548\end{array}$ \\
\hline
\end{tabular}

Values in bold type indicate a clinically important change in functional residual capacity after two weeks. 
eight after the active treatment. One infant who responded after the placebo period (functional residual capacity increased by $29 \%$ ) showed a $40 \%$ improvement after the active period and became symptom free during two weeks treatment with terbutaline. The other infant's functional residual capacity improved by $28 \%$ after placebo, and by $22 \%$ after active treatment.

The response to treatment with terbutaline did not seem to be greater in the older infants, as the youngest infant in the study group (postnatal age 8 months) had a clinically important change in functional residual capacity in response to terbutaline and was symptom free at the end of the active treatment period.

\section{Discussion}

These results show that inhaled bronchodilator treatment with a simple spacer device may reduce symptoms and improve respiratory function in infants who were born preterm and who have recurrent respiratory symptoms.

Administration of the bronchodilator resulted in an increase in functional residual capacity both immediately and during the two week active period. This latter change was associated with an improvement in symptom scores and so we felt that this increase in functional residual capacity reflected an improvement in lung function, probably by a reduction in gas trapping. This hypothesis is supported by our findings among children aged between 2 and 5 years with severe asthma, in whom bronchodilator treatment also relieved symptoms at the same time as increasing functional residual capacity. ${ }^{9}$

Lung function was assessed by measurement of functional residual capacity by helium gas dilution. Our median functional residual capacity results tend to be higher than other published ranges, ${ }^{10}$ but unlike many previous studies our population were all born preterm and this may explain the difference in results. Within the study group there was variation in the functional residual capacity results when they were related to body weight; this variation may be explained by the varied past medical histories of our patients. Although all were born prematurely, the gestational age at birth varied from 25-36 weeks and so they had different degrees of neonatal respiratory disease and need different treatments. Despite this variation of functional residual capacity among patients, however, eight had clinically important changes in functional residual capacity after two weeks' treatment with a bronchodilator, compared with only two after receiving the placebo.

This study was not randomised and all children received placebo then active treatment. Clinical improvement over the four week study period may have influenced the results but this seems unlikely as there has been no change in the frequency of symptoms for at least four weeks before the trial. The parents keeping the diary cards were, however, unaware of whether their infant was receiving placebo or active treatment, and the functional residual capacity data were also analysed without this information. The infants showed changes in functional residual capacity immediately in response to terbutaline after the active period alone, and significant changes in functional residual capacity compared with their baseline values after the two week active and not the placebo period. These changes in respiratory function suggest that the reduction in symptom scores over the second two weeks of the study does indeed reflect a response to bronchodilator treatment.

The improvement in lung function after treatment with the bronchodilator is perhaps surprising as it has previously been suggested that young children may be unresponsive to bronchodilator treatment. ${ }^{11}$ Lenney and Milner measured total respiratory resistance before and after treatment with nebulised salbutamol in wheezing children aged 7-43 months. ${ }^{11}$ Bronchodilators were apparently ineffective in improving lung function in wheezy infants less than 18 months of age. This apparent insensitivity was explained by the relative immaturity of lung receptors in younger children. The reproducibility of their plethysmographic measurements is not reported and thus one cannot interpret whether they were able to detect accurately minor but clinically important changes.

More recently Prendiville $e t a l$, using a histamine challenge test and measuring flow volume curves during forced expiration with a pressure jacket, suggested that infants as young as 3 months of age may respond to bronchodilator treatment, because treatment with a bronchodilator had been shown to reduce histamine induced responsiveness by at least 16 times. ${ }^{12}$ Other authors have reported that bronchodilators may be effective in younger infants-for example, those still in the neonatal intensive care unit. Wilkie and Bryan showed a significant decrease in resistance and an increase in compliance in response to both salbutamol and ipratropium bromide. ${ }^{13}$ Sosulski et al studied 80 infants with chronic lung disease, all of whom were still dependent on assisted ventilation, at a mean postnatal age of 13 weeks. ${ }^{14}$ They too showed a significant reduction in resistance and increase in compliance after terbutaline had been given.

The method of giving bronchodilator treatment to young children influences its efficacy. In children under the age of 3 , successful unaided use of a metered dose inhaler is unpredictable, especially during wheezing attacks. ${ }^{15}$ Consequently, expensive nebulisers had been used for giving bronchodilators. Problems (not only with cost) occur, however, with compressor driven nebulisers, which include the potential for the delivery of excessive doses of bronchodilator, ${ }^{16}$ the need for a power source to operate the delivery device, and nosocomial infections after failure to clean the nebulisers regularly. ${ }^{17}$ O'Callaghan et al also showed that the osmolality and acidity of the nebuliser solution is critically important, and a paradoxical impairment of lung function may result from nebulised salbutamol. ${ }^{18}$ Simple spacer devices, ${ }^{19}$ as used in this study, are not associated with such problems, and even during an acute asthmatic attack, children have appreciable bronchodilation after treatment given with a spacer device. ${ }^{20}$

We conclude that regular bronchodilator 
treatment by inhalation with the coffee cup technique is helpful for preterm infants with recurrent respiratory symptoms in the first two years of life.

Dr B Yuksel and Dr I Maconochie are research fellows supported by the Asthma Research Council.

1 Greenspan J, Abbasi S, Bhutani V. Sequential changes in pulmonary mechanics in the very low birth weight $(<1000$

2 O'Brodovich HM, Mellins RB. Bronchopulmonary dysplasia: unresolved neonatal acute lung injury. Am Rev Respir Dis 1985;132:694-709.

3 Sauve RS, Singhal N. Long term morbidity of infants with bronchopulmonary dysplasia. Pediatrics 1985;76:725-33.

4 Andreasson B, Lindroth M, Martensson W, Swenningsen NW, Jonson B. Lung function eight years after neonatal ventilation. Arch Dis Child 1989;64:108-13.

5 Bowman E, Yu V. Continuing morbidity in extremely low birthweight infants. Early Hum Dev 1989;18:165-74.

6 Smyth J, Tabachnik E, Duncan WJ, Reilly BJ, Levison H. Pulmonary function and bronchial hyperreactivity in long term survivors of bronchopulmonary dysplasia. Pediatrics term survivors

7 Park ES, Golding J, Carswell F, Stewart-Brown S. Pre-school whee:ing and prognosis at ten. Arch Dis Child 1986;64: 642-6.

8 Greenough A, Maconochie I, Gamsu HR. Do respiratory problems cease when preterm babies leave neonatal inten sive care? European Respiratory fournal 1988; ( (supp 2): 227.

9 Greenough A, Pool JB, Price JF. Changes in functional residual capacity in response to bronchodilator therapy among young asthmatic children. Pediatr Pulmonol 1989;7: 8-11.

10 Gaultier C, Boule M, Allaire Y, Clement A, Girard F. Growth of lung volumes during the first three years of life. Bull Eur of lung volumes during the first three year
Physiopathol Respir 1979;15:1103-16.

11 Lenney W, Milner A. At what age do bronchodilators work?

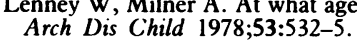

12 Prendiville A, Green S, Silverman M. Airway responsiveness in wheezy infants: evidence for functional beta-adrenergic in whee\%y infants: evidence for funct

13 Wilkie RA, Bryan MH. Effect of bronchodilators on airway resistance in ventilator-dependent neonates with chronic lung disease. f Pediatr 1987;111:278-82.

14 Sosulski R, Abbasi S, Bhutani V, Fox W. Physiological effects of terbutaline on pulmonary function of infants with bronchopulmonary dysplasia. Pediatr Pulmonol 1986;2: 269-73.

15 Conner WT, Dolovich MB, Frame RA, Newhouse MT. Reliable salbutamol administration in 6 to 36 month-old children by means of a metered dose inhaler and aerochamber with mask. Pediatr Pulmonol 1989;6:263-7.

16 Amonymous. The nebuliser epidemic [Editorial]. Lancet 1984;ii:789-90.

17 Pierce AK, Sandford JP, Thomas GD, Leonard JS. Long term evaluation of decontamination of inhalation therapy equipment and occurrence of necrotising pneumonia. $N$ equipment and occurrence of

18 O'Callaghan C, Milner AD, Swarbrick A. Paradoxical deterioration in lung function after nebulized salbutamol in wheery infants. Lance 1986;

19 O'Callaghan C, Milner AD, Swarbrick A. Spacer device with face mask attachment for giving bronchodilators to infants with asthma. $\mathrm{Br} M e d \mathcal{F}$ 1989;298:160-1.

20 Benton G, Thomas R, Nickerson B, McQuitty J, Okikawa J. Experience with a metered-dose inhaler with a spacer in the pediatric emergency department. Am $\mathcal{F}$ Dis Child 1989;143: 678-81.

\section{British Paediatric Association Annual Meetings}

University of Warwick:

16-19 April 1991

7-10 April 1992

20-23 April 1993

12-15 April 1994 